\title{
Mitochondrial Protection Partly Mitigates Kidney Cellular Senescence in Swine Atherosclerotic Renal Artery Stenosis
}

\author{
Seo Rin Kim ${ }^{a} \quad$ Alfonso Eirin ${ }^{a} \quad$ Xin Zhang ${ }^{a} \quad$ Amir Lerman ${ }^{b} \quad$ Lilach O. Lerman ${ }^{a, b}$ \\ aDivision of Nephrology and Hypertension, Mayo Clinic, Rochester, MN, USA, ${ }^{\mathrm{b} C a r d i o v a s c u l a r}$ Diseases, \\ Mayo Clinic, Rochester, MN, USA
}

\section{Key Words}

Atherosclerotic renal artery stenosis $\bullet$ Senescence $・$ Elamipretide $\bullet$ Mitochondria

\begin{abstract}
Background/Aims: Atherosclerotic renal artery stenosis (ARAS) may cause kidney injury and mitochondrial dysfunction, which is linked to cellular senescence. Elamipretide, a mitochondria-targeted peptide, improves renal function in ARAS, but whether it alleviates senescence is unknown. We hypothesized that elamipretide would reduce senescence stenotic kidney (STK) in ARAS. Methods: Domestic pigs were randomized to control and unilateral ARAS untreated or treated with subcutaneous elamipretide ( $5 \mathrm{~d} / \mathrm{wk})$ for 4 weeks starting after 6 weeks of ARAS or sham ( $n=6$ each). After completion of treatment, STK renal blood flow (RBF) and glomerular filtration rate (GFR) were assessed in-vivo using multi-detector computed-tomography. Renal fibrosis and oxidative stress were analyzed in trichrome- and dihydroethidium-stained slides, respectively. Mitochondrial markers involved in the electrontransport chain (COX4, ATP/ADP ratio), biogenesis (PGC1 $\alpha$, PPAR $\alpha$ ), dynamics (MFN2, DRP1), and mitophagy (parkin, p62) were measured in the kidney using ELISA, western-blot, and immunohistochemistry. Cellular senescence (senescence-associated $\beta$-galactosidase and heterochromatin foci, phosphorylated-H2AX, and p16/21/53) and senescence-associated secretory phenotype (SASP; PAI-1, MCP-1, TGF $\beta$, and TNF $\alpha$ ) markers were studied by microscopy, quantitative reverse transcription-polymerase chain reaction, and western-blot. Results: Blood pressure was elevated whereas STK-RBF and GFR were decreased in ARAS pigs, and tissue scarring was increased. ARAS induced STK cellular senescence and accumulated dysfunctional mitochondria, which were associated with cardiolipin loss, upregulated mitochondrial biogenesis, and defective mitophagy. Elamipretide normalized STK-RBF and GFR, alleviated fibrosis and oxidative stress, and restored mitochondrial cardiolipin, biogenesis, and mitophagy in ARAS, but did not change SASP markers, and attenuated only senescenceassociated $\beta$-galactosidase activity and $p 53$ gene expression. Conclusion: Mitochondrial protection improved renal function and fibrosis in the ARAS STK, but only partly mitigated
\end{abstract}




\section{Cellular Physiology Cell Physiol Biochem 2019;52:617-632 \\ \begin{tabular}{ll|l} 
and Biochemistry & $\begin{array}{l}\text { DOI: 10.33594/000000044 } \\
\text { Published online: } 26 \text { March } 2019\end{array}$ & $\begin{array}{l}\text { C } 2019 \text { The Author(s). Published by } \\
\text { Cell Physiol Biochem Press GmbH\&Co. KG }\end{array}$
\end{tabular} \\ Kim et al.: Elamipretide in Stenotic Kidneys}

cellular senescence. This finding suggests that mitochondrial dysfunction may not be a major determinant of cellular senescence in the early stage of ARAS.

(C) 2019 The Author(s). Published by Cell Physiol Biochem Press GmbH\&Co. KG

\section{Introduction}

Atherosclerotic renal artery stenosis (ARAS) remains the leading cause of renovascular hypertension, and increases in prevalence due to aging of the population and increasing prevalence of atherosclerosis risk factors. As the disease progresses, ARAS results in downstream renal pathological alterations with gradual functional loss [1-3]. We have recently demonstrated mitochondrial dysfunction in ARAS [3], which partly mediates ARASinduced kidney damage secondary to prolonged kidney ischemia and dyslipidemia [3].

Cellular senescence is an irreversible proliferation arrest in response to stress [4]. Senescent cells not only have anti-apoptotic and pro-survival defenses, but frequently express the senescence-associated secretory phenotype (SASP) which consolidates senescence and adversely influences adjacent cells [5]. Cellular senescence has been shown to contribute to the pathogenesis of atherosclerosis. Atherosclerotic lesions show senescence-associated $\beta$-galactosidase (SA- $\beta$-Gal) expression [6], and obesity promotes vascular senescence, making the tissue susceptible to ischemia [7]. In the kidney, senescent cells have been detected in acute ischemic injury [8]. However, the involvement of cellular senescence in chronic renal damage remains unclear.

Mitochondrial dysfunction and cellular senescence are both important contributors to aging and age-related disease [9]. The importance of mitochondria in eliciting cellular senescence, especially the pro-inflammatory phenotype [10] is correlated with production of mitochondrial reactive oxygen species (ROS) [11], whereas senescent cells conversely accumulate dysfunctional mitochondria [12]. This bidirectional link between senescence and mitochondria might be involved in stenotic kidney (STK) injury in ARAS, yet this link in ARAS has not been demonstrated.

Elamipretide is a novel tetrapeptide that selectively and transiently concentrates in the inner mitochondrial membrane, where it binds to and stabilizes cardiolipin, facilitating efficient electron transport and preventing apoptosis [13]. We have shown that elamipretide in ARAS blunts oxidative stress, microvascular loss, and tissue injury, and improves renal function [3]. However, whether elamipretide would alleviate renal senescence is unknown.

This study was designed to test the hypothesis that mitochondrial dysfunction in ARAS may account for STK cellular senescence, and thereby senescence-associated secretory phenotype (SASP). Furthermore, we hypothesized that due to its mitochondrial-protective properties, elamipretide would alleviate STK cellular senescence.

\section{Materials and Methods}

This study was approved by the Institutional Animal Care and Use Committee. Twenty-four domestic female pigs were studied during 16 weeks of observation. At 3 months of age, pigs were randomized to ARAS or Normal without or with elamipretide treatment (ARAS+ELAM and Normal+ELAM; n=6 each group). Normal pigs were fed with isocaloric diets of standard chow, and ARAS pigs with a high-fat diet containing $2 \%$ cholesterol (Harlan Teklad, Madison, WI) [14] starting 6 weeks prior to induction of renal artery stenosis. All animals had free access to water. Six weeks after initiation of diet, pigs were anesthetized with $0.25 \mathrm{~g}$ of intramuscular tiletamine hydrochloride/zolazepam hydrochloride and $0.5 \mathrm{~g}$ of xylazine, and maintained with intravenous ketamine $(0.2 \mathrm{mg} / \mathrm{kg} / \mathrm{min})$ and xylazine $(0.03 \mathrm{mg} / \mathrm{kg} / \mathrm{min})$. In ARAS groups, RAS was induced by placing a local irritant coil in the right main renal artery, as described [15]. The Normal groups underwent a sham procedure. Six weeks after induction of RAS, the degrees of stenosis were determined by renal angiography, and the treatment groups started with subcutaneous injections of elamipretide (MTP-131, SS-31, Stealth Biotherapeutics, Newton Centre, MA), $0.1 \mathrm{mg} / \mathrm{kg}$ in $1 \mathrm{~mL}$ of phosphate-buffered saline once daily 5 days/week. A vehicle was injected in the control pigs [3]. Four weeks after initiation 


\section{Cellular Physiology Cell Physiol Biochem 2019;52:617-632

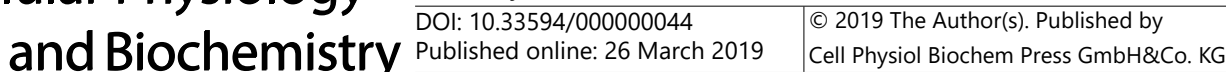 \\ Kim et al.: Elamipretide in Stenotic Kidneys}

of treatment, the pigs were again anesthetized. The degree of stenosis was determined by angiography, and systemic venous blood samples collected for lipid profile and serum creatinine (DiaSorin, Stillwater, MN, USA) measurements. Renal hemodynamics and function were assessed in vivo using multi-detector computed tomography (MDCT). After completion of all in vivo studies and 30-60 min after the last dose of elamipretide, pigs were euthanized (sodium pentobarbital, $100 \mathrm{mg} / \mathrm{kg}$ ). The kidneys were dissected, and sections preserved fresh frozen or in formalin for ex vitro studies.

\section{Renal hemodynamics and function}

After 4 weeks of treatment, renal blood flow (RBF) and glomerular filtration rate (GFR) were assessed using MDCT (Somatom Sensation 64; Siemens Medical Solutions, Forchheim, Germany) [15, 16] by acquiring 140 consecutive scans ( $330 \mathrm{~ms}$ each) after a central venous injection of iopamidol $(0.5 \mathrm{~mL} / \mathrm{kg}$ per 2 seconds). MDCT images were reconstructed and displayed with the Analyze ${ }^{\circledR}$ software package (Biomedical Imaging Resource, Mayo Clinic, Rochester, MN). For data analysis, time-attenuation curves were generated from regions of interest (ROIs) in the aorta, renal cortex, and medulla to obtain measures of renal function [16]. Blood pressure was measured in all animals using an arterial catheter during MDCT.

\section{Fibrosis and oxidative stress}

Kidney tissue was embedded in paraffin and sectioned $(5 \mu \mathrm{m})$ for Masson's trichrome staining. Glomerulrosclerosis and interstitial fibrosis was analyzed in 10-15 fields per slide (ZEN; Carl Zeiss, Oberkochen, Germany). Sclerotic glomeruli were counted, and their percentage out of 100 glomeruli calculated [17]. The in situ production of superoxide anion was studied in renal tissue using dihydroethidium (DHE) staining and fluorescence microscopy [3]. The degree of interstitial fibrosis in the renal cortex and DHE area was semi-automatically quantified using a masking algorithm based on color thresholding and edge detection in a computer-aided image-analysis program AxioVision ${ }^{\odot}$ (Carl Zeiss) and expressed as an average percent of total field area [17].

\section{Mitochondrial function and biogenesis}

Total cardiolipin content was measured by enhanced multidimensional mass spectrometry based shotgun lipidomics, as previously described [3]. Activity of mitochondrial respiratory chain complex IV subunit COX-4 was determined by ELISA (Abcam) [18]. To evaluate mitochondrial biogenesis, renal protein expression of peroxisome proliferator-activated receptor gamma coactivator (PGC)1- $\alpha$ (1:1000, Abcam), peroxisome proliferator-activated receptor- $\gamma$-coactivator (PPAR)- $\alpha$ (1:1000, Abcam), mitofusin (MFN)-2 (1:1000 Cell Signaling), dynamin-related protein (DRP)-1 (1:1000 Cell Signaling), P62 (1:1000, Abcam), and GAPDH in $100 \mu \mathrm{g}$ of protein from each homogenized kidney tissue sample was measured by Western blot.

In addition, MITO-ISO kit (ScienCell, Carlsbad, CA) was used for mitochondrial isolation. Then protein expression of Parkin (1:200, Santa Cruz) and COX-IV (1:1000, Cell Signaling) was measured by Western blot and quantified by ImageJ software. Renal ATP and ADP content was assessed in isolated mitochondria by colorimetric methods and expressed as ratio [19]. To assess mitophagy, colocalization of Parkin with Tom20 , a mitochondrial outer membrane protein, was evaluated in renal paraffin-sections ( $5 \mu \mathrm{m}$ thick). Confocal microscopy demonstrated the immunostaining of Parkin (Santa Cruz, Alexa Fluoro 594, red) and Tom-20 (Santa Cruz, Alexa Fluor 488, green). The percent area of co-localized Parkin and Tom-20 was quantified semiautomatically in 10-15 random fields using AxioVision ${ }^{\odot}$ [20].

\section{Senescence and SASP markers}

Senescence-associated $\beta$-galactosidase (SA- $\beta$-gal) staining was done using the Senescence $\beta$-Galactosidase Staining Kit (\#9860, Cell Signaling, Boston, MA), as described [21]. Sections were counterstained with eosin, dehydrated, and mounted. SA- $\beta$-Gal-positive area was determined in ten randomly chosen fields per section at $\times 20$ magnification and assessed for development of blue color. The degree of senescence was expressed as an average of percent SA- $\beta$-Gal-positive to total field area [22]. To assess p16 protein expression, p16 colorimetric staining (Abcam) was done on formalin-fixed paraffinembedded (FFPE) renal sections. To assess proliferation and senescence-associated heterochromatin foci (SAHF), FFPE sections were stained with Ki67 (Abcam) and histone H3K9 trimethyl (Epigentek), respectively, and mounted with DAPI (Invitrogen) $[23,24]$. To evaluate senescence in endothelial 


\section{Cellular Physiology Cell Physiol Biochem 2019;52:617-632 \\ \begin{tabular}{ll|l} 
and Biochemistry & $\begin{array}{l}\text { DOI: 10.33594/000000044 } \\
\text { Published online: } 26 \text { March } 2019\end{array}$ & $\begin{array}{l}\text { C } 2019 \text { The Author(s). Published by } \\
\text { Cell Physiol Biochem Press GmbH\&Co. KG }\end{array}$ \\
\hline
\end{tabular} \\ Kim et al.: Elamipretide in Stenotic Kidneys}

cells, renal cryosections were co-stained with fluorogenic $\beta$-galactosidase detection kit (SPiDER- $\beta$ Gal, Dojindo) and CD31 (ABD Serotec). The \% of positive cells was manually computed in ten random fields per section at $\mathrm{x} 40$ magnification. Protein expression of $\gamma$-phosphorylated histone-2AX $(\gamma \mathrm{H} 2 \mathrm{AX})(1: 1000$ Abcam), total H2AX (1:1000 Abcam), plasminogen activator inhibitor (PAI)-1 (1:1000 Abcam), monocyte chemoattractant protein (MCP)-1 (1:10 Abcam), transforming growth factor (TGF)- $\beta$ (1:1000 Abcam), and

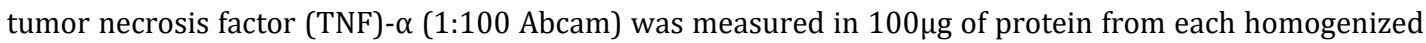
kidney tissue sample by Western blot [20]. GAPDH (1:5000 Abcam) was used as loading control and band intensity quantified using ImageJ software. In addition, fluorimetric SA- $\beta$-Gal activity was assayed using a Cellular Senescence Activity Assay Kit (Enzo Life Sciences, Farmingdale, NY). Renal gene expression of $p 16$ (Hs00923894), $p 21$ (Hs00355782), $p 53$ (Hs01034249), Activin-A (Hs01081598), and GAPDH (Hs02786624) was assessed on Applied Biosystems ViiA7 Real-Time PCR systems using the delta-delta CT method with validated TaqMan primers from Thermo Fisher Scientific (Waltham, MA) [25].

\section{Statistical analysis}

Statistical analysis was performed using JMP software version 13.0 (SAS Institute, Cary, NC). Results are presented as mean $\pm \mathrm{SD}$ for normally distributed variables and as median (interquartile range) for data without normal distribution. Parametric (one-way analysis of variance followed by Student's t-test) and non-parametric (Kruskal-Wallis followed by Wilcoxon) test were used for comparisons among groups. A P value $\leq 0.05$ was considered statistically significant.

\section{Results}

\section{Characteristics and renal function}

The degree of stenosis was comparable in untreated and treated ARAS groups $(\mathrm{P}=0.63)$ (Table 1). ARAS increased blood pressure ( $\mathrm{P}=0.03$ vs. Normal) and lipid levels. ARAS also lowered STK GFR ( $\mathrm{P}=0.04$ vs. Normal) and elevated serum creatinine (Fig. $1 \mathrm{~A}, \mathrm{P}=0.008$ vs. Normal). Elamipretide improved STK-GFR and RBF ( $\mathrm{P}=0.002$ and 0.04 vs. ARAS, respectively) without affecting lipid profile in ARAS pigs. ELAM did not change blood pressure, renal function, or RBF in Normal pigs.

\section{Glomerulosclerosis, tubulointerstitial fibrosis, and oxidative stress}

ARAS developed STK fibrosis and glomerulosclerosis $(\mathrm{P}=0.001$ and $\mathrm{P}<0.0001$ vs. Normal, respectively), but elamipretide abolished fibrosis ( $\mathrm{P}=0.02$ vs. ARAS) and alleviated, albeit not normalized, glomerulosclerosis ( $\mathrm{P}<0.0001$ vs. ARAS) (Fig. 1B). Renal production of superoxide anion was increased in ARAS ( $\mathrm{P}=0.005$ vs. Normal) and attenuated after elamipretide treatment ( $\mathrm{P}=0.005$ vs. ARAS) (Fig. 2A).

\section{Mitochondrial markers}

Total cardiolipin content was decreased in ARAS compared to Normal $(\mathrm{P}=0.03)$ and restored after elamipretide treatment ( $\mathrm{P}=0.008$ vs. ARAS) (Fig. 2B). COX-4 activity was unchanged in the ARAS STK compared to Normal, but higher in ARAS+ELAM vs. ARAS $(\mathrm{P}=0.02)$. Mitochondrial ATP/ADP ratios were not different among the groups $(\mathrm{P}=0.18)$. Renal

Table 1. Characteristics of normal and atherosclerotic renal artery stenosis (ARAS) pigs untreated or treated with elamipretide (ELAM) for 4 weeks ( $n=6$ each). ${ }^{*} \mathrm{p}<0.05$ vs. Normal. Data are expressed as median (interquartile range)

\begin{tabular}{lcccc}
\hline Paramter & Normal & Normal+ELAM & ARAS & ARAS+ELAM \\
\hline Degree of stenosis (\%) & - & - & $95(67.5-99.5)$ & $85(62.5-87.5)$ \\
Total cholesterol (mg/dl) & $87(77-113.5)$ & $87(77.5-91)$ & $519(453-545)^{*}$ & $484.5(450.5-$ \\
$613.7)^{*}$ & $285.7(231.3-$ \\
Low density lipoprotein cholesterol & $50.8(36.6-57)$ & $34.6(29.1-$ & $324.6(245-375)^{*}$ & $435.6)^{*}$ \\
(mg/dl) & $96.5(89.2-$ & $40.5)$ & $139.7(99.3-$ & $117.3(91.7-137.3)$ \\
Mean arterial pressure (mmHg) & $103.9)$ & $91.7(84-101.3)$ & $170.3)^{*}$ & \\
\hline
\end{tabular}




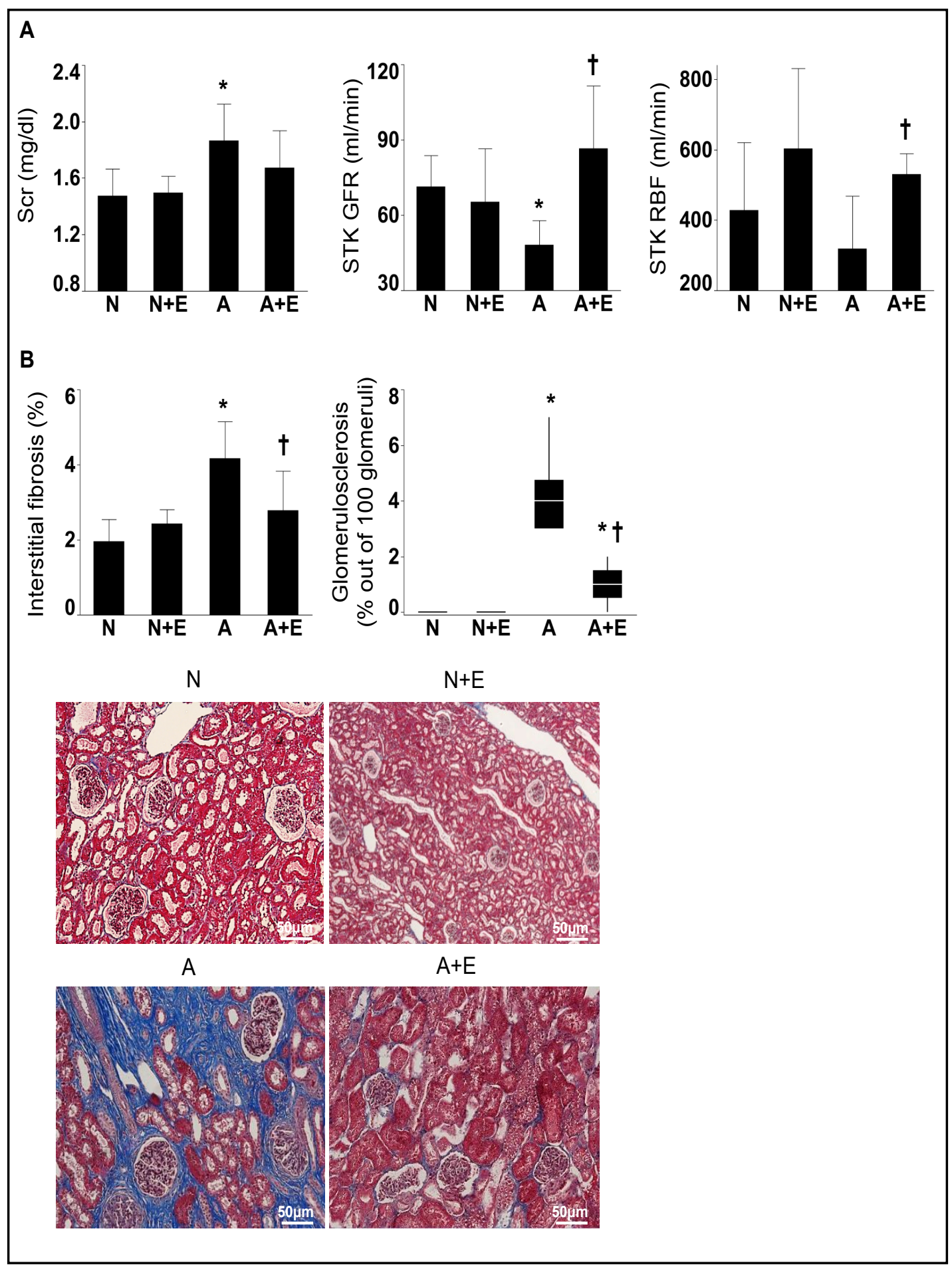

Fig. 1. Elamipretide improves stenotic kidney (STK) function and blunts fibrosis. A. Atherosclerotic renal artery stenosis (ARAS) pigs showed a decrease in both STK and overall kidney function. Elamipretide improved serum creatinine, STK glomerular filtration rate (GFR), and renal blood flow (RBF). B. ARAS developed STK fibrosis (trichrome, blue) and glomerulosclerosis, which elamipretide alleviated. N, Normal; $\mathrm{N}+\mathrm{E}$, Normal+elamipretide; A, ARAS; A+E, ARAS+elamipretide. ${ }^{*} \mathrm{P}<0.05$ vs. Normal, $\uparrow \mathrm{P}<0.05$ vs. ARAS. 


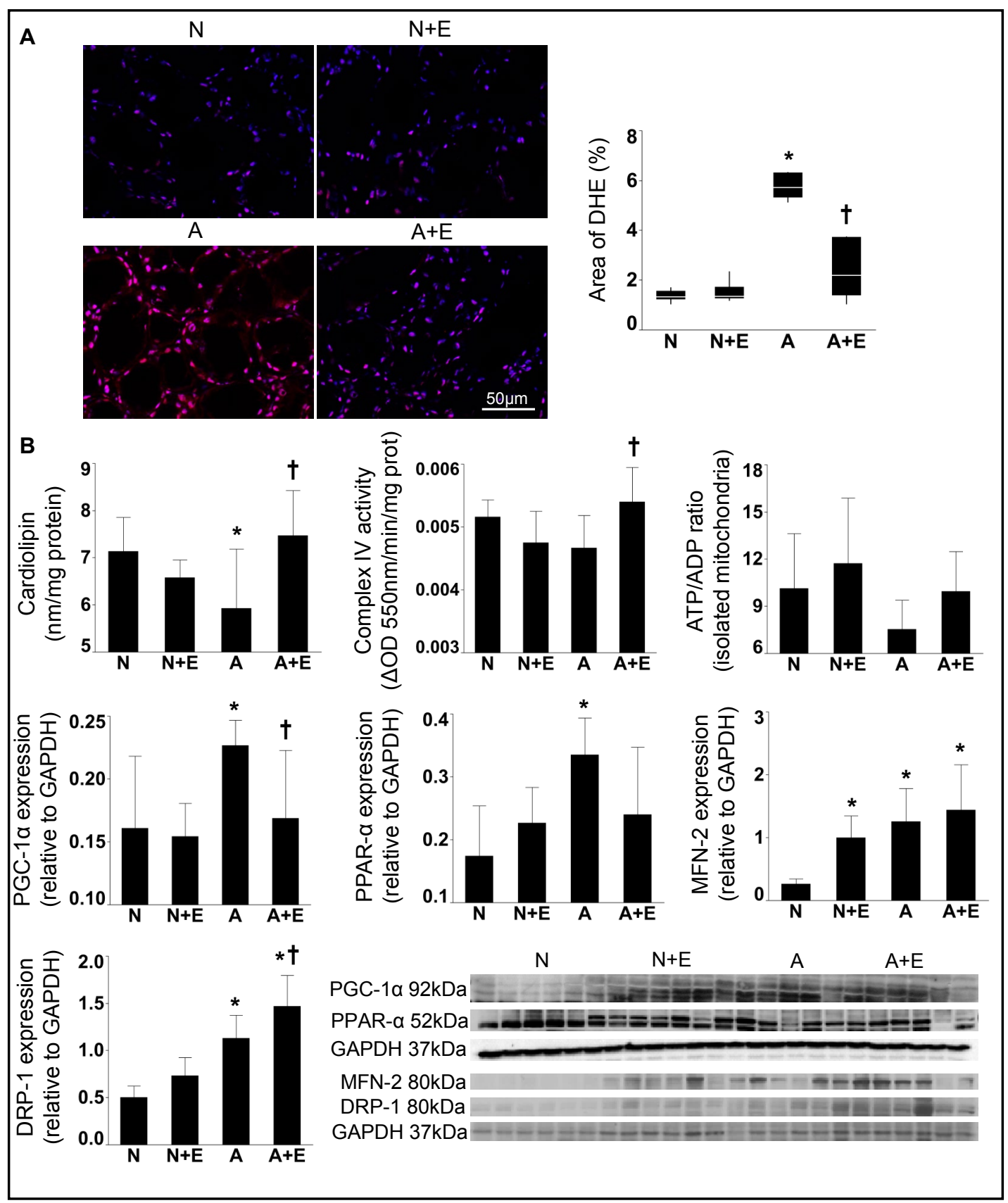

Fig. 2. Elamipretide alleviates oxidative stress and restores renal mitochondrial function. A. Renal production of superoxide anion (DHE: pink, DAPI: blue) was increased in atherosclerotic renal artery stenosis (ARAS) and attenuated by elamipretide. B. Elamipretide increased total cardiolipin content and complex-IV activity in the ARAS kidney, while mitochondrial ATP/ADP ratios were not different among the groups. Renal expressions of PGC- $1 \alpha$ and PPAR- $\alpha$ increased in ARAS, and elamipretide reversed them. Renal expressions of MFN-2 and DRP-1 were elevated in both ARAS and ARAS+elamipretide kidneys. N, Normal; $\mathrm{N}+\mathrm{E}$, Normal+elamipretide; A, ARAS; A+E, ARAS+elamipretide. ${ }^{*} \mathrm{P}<0.05$ vs. Normal, $+\mathrm{P}<0.05$ vs. ARAS.

expression of the mitochondrial biogenesis markers, PGC- $1 \alpha$ and PPAR- $\alpha$, was increased in ARAS compared with Normal ( $\mathrm{P}=0.04$ and 0.004 , respectively), and elamipretide tended to normalize them ( $\mathrm{P}=0.05$ and $0.07 \mathrm{vs}$. ARAS, respectively). ARAS increased STK expression of the fusion marker MFN-2 ( $\mathrm{P}=0.002$ vs. Normal), which elamipretide did not affect in ARAS $(\mathrm{P}=0.5)$, but elevated in Normal kidneys ( $\mathrm{P}=0.01$ vs. Normal). Renal expression of $\mathrm{DRP}-1$ in 
ARAS was higher than in Normal $(\mathrm{P}=0.0002)$ and further elevated in ARAS+ELAM ( $\mathrm{P}=0.02)$. In immunofluorescent staining, the percent area of Parkin-TOM20 co-localization, indicating mitophagy, was lower in ARAS than in Normal $(\mathrm{P}=0.01)$ and restored in ARAS+ELAM $(\mathrm{P}=0.005$ vs. ARAS) (Fig. 3A). Parkin expression in isolated mitochondria tended to decrease in ARAS vs. Normal $(\mathrm{P}=0.08)$, and increased in ARAS+ELAM compared with ARAS $(\mathrm{P}=0.02)$ (Fig. 3B). P62 expression was higher in Normal+ELAM, ARAS, and ARAS+ELAM

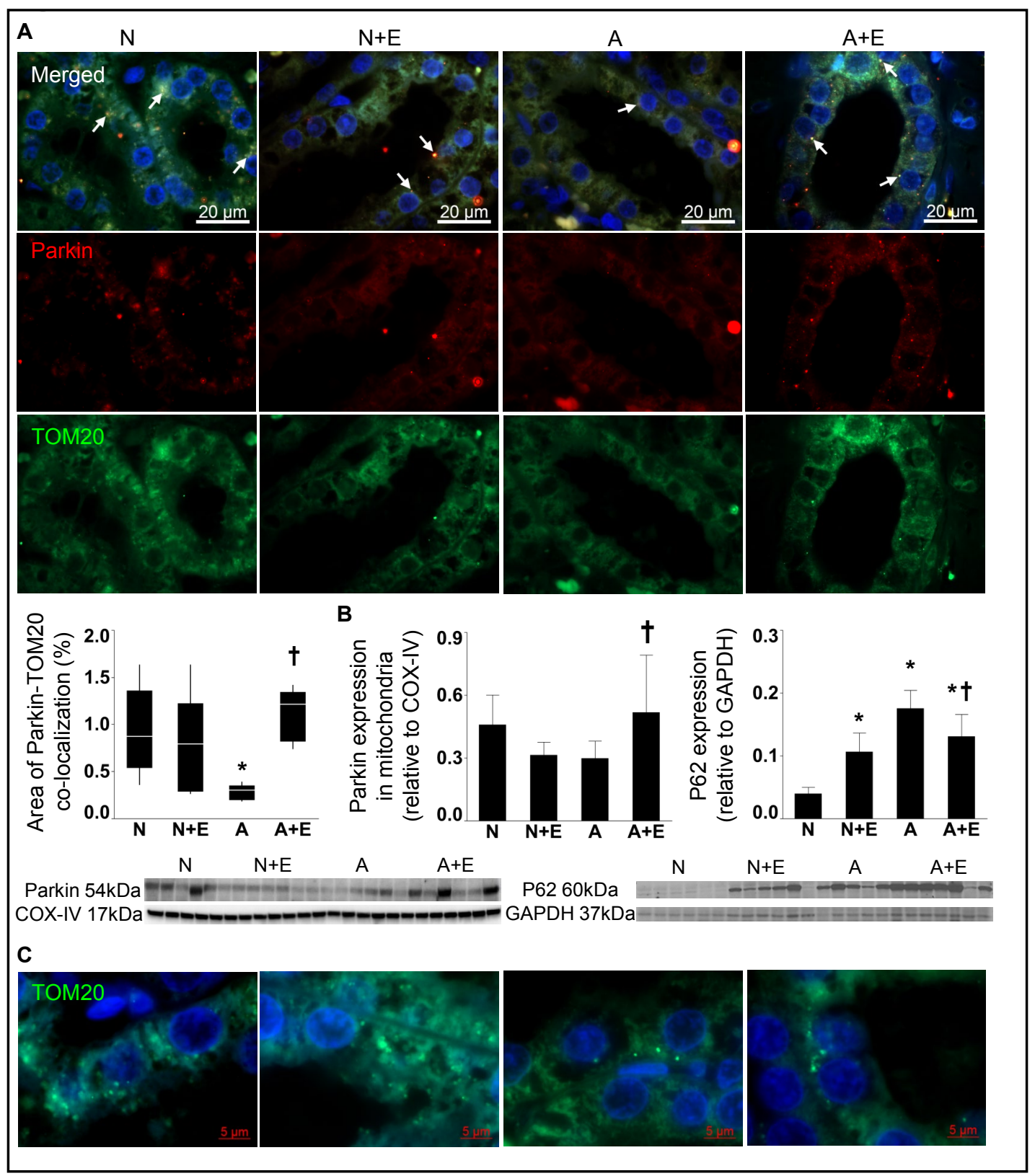

Fig. 3. Elamipretide restores mitophagy in atherosclerotic renal artery stenosis (ARAS) kidneys. A. The area of TOM20 (green) and Parkin (red) co-staining in renal tubules (arrow), reflecting mitophagy, was decreased in ARAS and restored in ARAS+elamipretide. Blue, DAPI. B. Elamipretide increased Parkin in mitochondria and decreased P62 expression in the ARAS stenotic kidneys. C. Representative confocal images of TOM20 (green) at 100X magnification. In ARAS, mitochondria were more round and fewer than normal groups, and dispersed in the cytoplasm. Despite a significant increase in mitochondrial density, some ARAS+elamipretide mitochondria remained fragmented and located in perinuclear area. N, Normal; N+E, Normal+elamipretide; A, ARAS; A+E, ARAS+elamipretide. ${ }^{*} \mathrm{P}<0.05$ vs. Normal, $+\mathrm{P}<0.05$ vs. ARAS. 
Fig. 4. Elamipretide decreases senescenceassociated $\beta$-galactosidase (SA- $\beta$-gal) activity in the stenotic kidneys (STKs). A. SA- $\beta$-Gal positive area (blue) increased both in the medulla and cortex of atherosclerotic renal artery stenosis (ARAS) STK, and decreased after elamipretide. B. P16-positive cells were increased in ARAS and tended to remain elevated in ARAS+elamipretide compared to normal pigs. Renal tubular (yellow arrowhead), interstitial (red arrowhead), and endothelial (red arrow) cells were p16-postivie in ARAS. C. In ARAS, the number of Ki67-positive cells (pink) per field was not different from normal, but increased in ARAS+elamipretide compared to in normal pigs. D. The numbers of senescence-associated heterochromatin-foci (SAHF)-positive cells

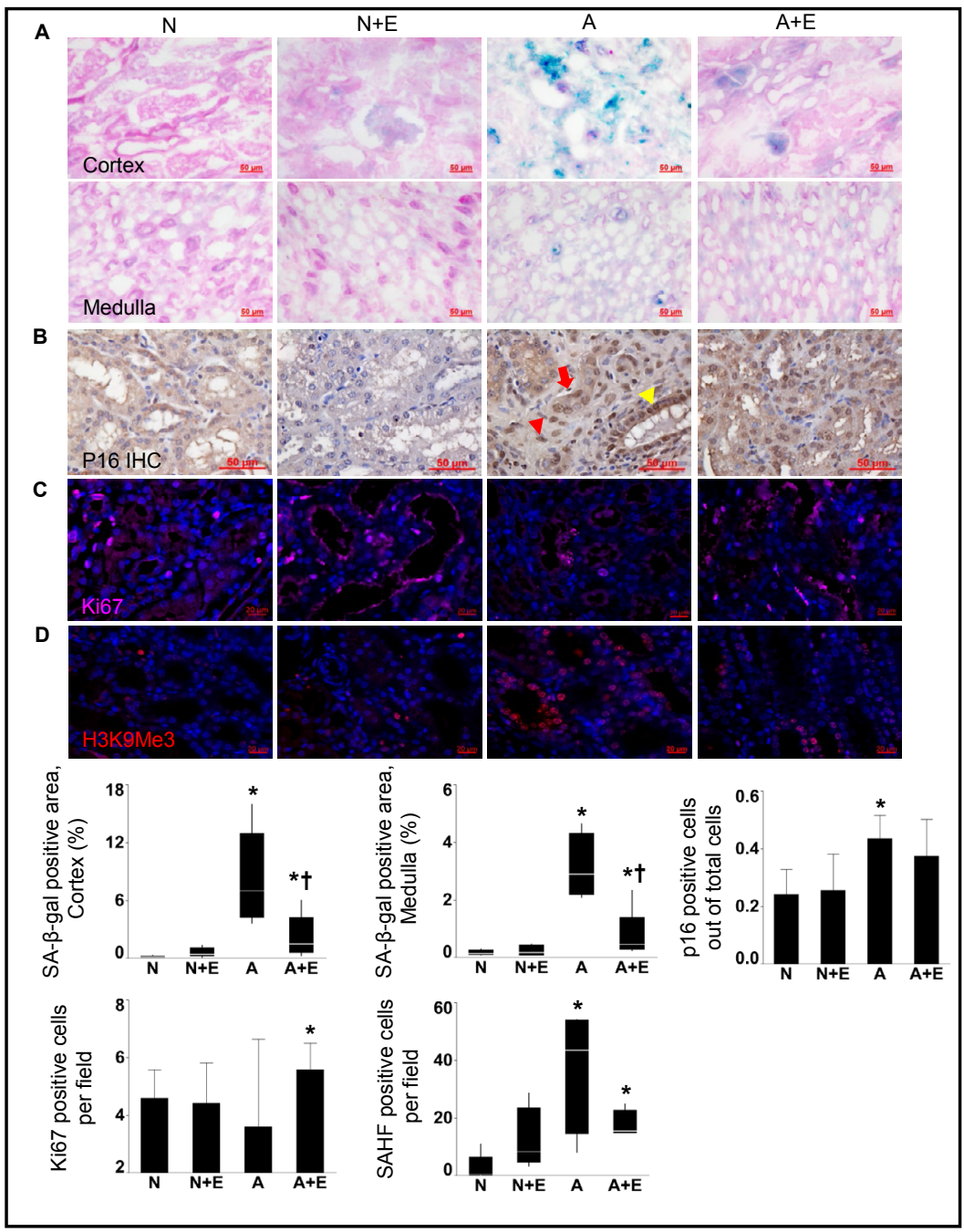
(red) per field increased in ARAS and persisted in ARAS+elamipretide compared to normal. N, Normal; N+E, Normal+elamipretide; A, ARAS; A+E, ARAS+elamipretide. ${ }^{*} \mathrm{P}<0.05$ vs. Normal, $\nmid \mathrm{P}<0.05$ vs. ARAS.

than in Normal kidneys $(\mathrm{P}=0.008, \mathrm{P}<0.0001$, and $\mathrm{P}<0.0001$, respectively), but was lower in ARAS+ELAM than in ARAS $(\mathrm{P}=0.02)$, suggesting that decreased mitophagy in ARAS was improved in ARAS+ELAM. In terms of morphology, ARAS mitochondria were fewer and more round than normal groups, and dispersed in the cytoplasm, showing mitochondrial damage (Fig. 3C). Despite a significant increase in mitochondrial density, some ARAS+ELAM mitochondria remained fragmented and located in perinuclear area, possibly due to the increase in mitochondrial fission and mitophagy.

\section{Renal senescence}

Positive SA- $\beta$-Gal staining was markedly increased in both the ARAS STK medulla and cortex compared with Normal $(\mathrm{P}=0.03$ and $\mathrm{P}=0.006$, respectively), and decreased after elamipretide (both $\mathrm{P}=0.02$ ), yet was not fully normalized (Fig. 4A). The number of p16+ cells increased or tended to increase in both ARAS and ARAS+ELAM (P=0.01 and 0.06 vs. normal, respectively) (Fig. 4B). Identified by location and morphology, renal tubular, interstitial, and endothelial cells were p16+ in ARAS. Furthermore, some endothelial cells in ARAS coexpressed SA- $\beta$-gal and CD31, underscoring endothelial cell senescence, which tended to decrease in ARAS+ELAM ( $\mathrm{P}=0.06$ vs. ARAS) (Fig. 5). In ARAS, the number of Ki67-positive 


\section{Cellular Physiology \begin{tabular}{ll|l} 
and Biochemistry & Dublished online: 26 March 2019 & $\begin{array}{l}\text { C } 2019 \text { The Author(s). Published by } \\
\text { Cell Physiol Biochem Press GmbH\&Co. KG }\end{array}$
\end{tabular}

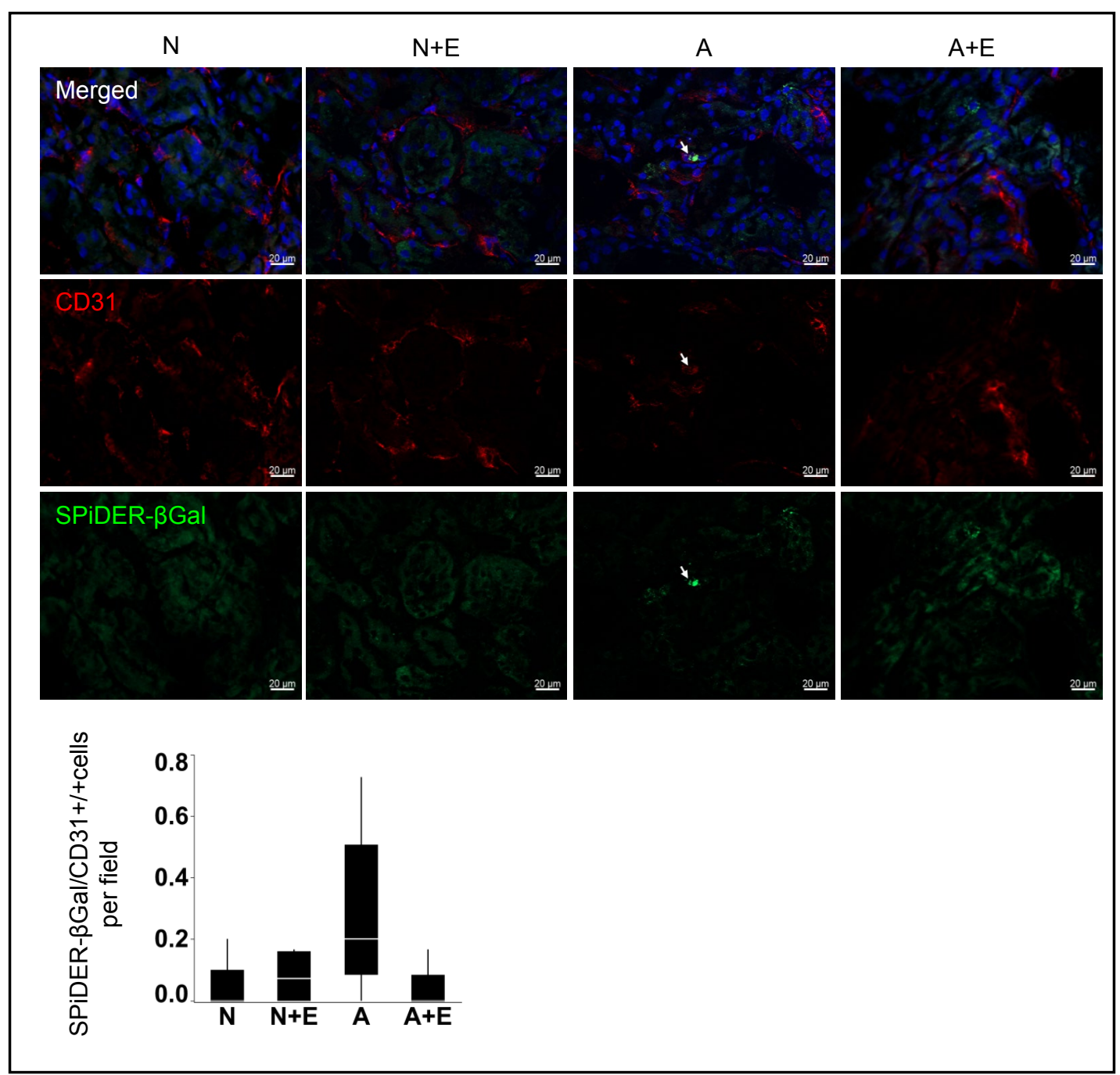

Fig. 5. Elamipretide slightly improves endothelial cell senescence. A few population of cells expressed both SPiDER- $\beta$ Gal (green) and CD31 (red) in atherosclerotic renal artery stenosis (ARAS), suggesting endothelial cell senescence, which tended to decrease in ARAS+elamipretide. N, Normal; N+E, Normal+elamipretide; A, ARAS; A+E, ARAS+elamipretide.

cells was not different from normal despite renal injury $(\mathrm{P}=0.31)$, whereas their number was increased in ARAS+ELAM compared to normal pigs (Fig. 4C, $\mathrm{P}=0.05$ ). The numbers of SAHF-positive cells per field were increased both in ARAS and ARAS+ELAM compared to normal (Fig. 4D, $P=0.04$ and 0.02 , respectively). Renal SA- $\beta$-Gal activity was higher in ARAS and ARAS+ELAM than in Normal (both $\mathrm{P}=0.01$ ), and elamipretide tended to decrease it, but this did not reach statistical significance (Fig. $6 \mathrm{~A}, \mathrm{P}=0.06$ vs. ARAS). H2AX activation (phosphorylated-to-total H2AX protein ratio) was elevated in the ARAS kidney ( $\mathrm{P}=0.008 \mathrm{vs}$. Normal), but unaffected by elamipretide ( $\mathrm{P}=0.8$ vs. ARAS) (Fig. 6B). While renal $p 16$ and $p 21$ gene expression did not differ among the groups ( $\mathrm{P}=0.14$ and 0.72 , respectively), $p 53$ gene expression was increased in ARAS ( $\mathrm{P}=0.03$ vs. Normal), decreased after elamipretide treatment (Fig. 6C, $\mathrm{P}=0.05$ vs. ARAS), and directly correlated with SA- $\beta$-Gal positivity in the ARAS STK cortex.

Expression of the SASP components PAI- 1 and MCP-1 was increased in both the ARAS $(\mathrm{P}=0.001$ and $\mathrm{P}=0.001$ vs. Normal, respectively) and ARAS+ELAM $(\mathrm{P}<0.0001$ and $\mathrm{P}=0.0002$ vs. Normal, respectively) STK (Fig. 6D), and TGF $\beta$ expression showed a similar pattern $(p=0.002$ and $p=0.0002$ vs. Normal, respectively). TNF $\alpha$ expression was unchanged among 


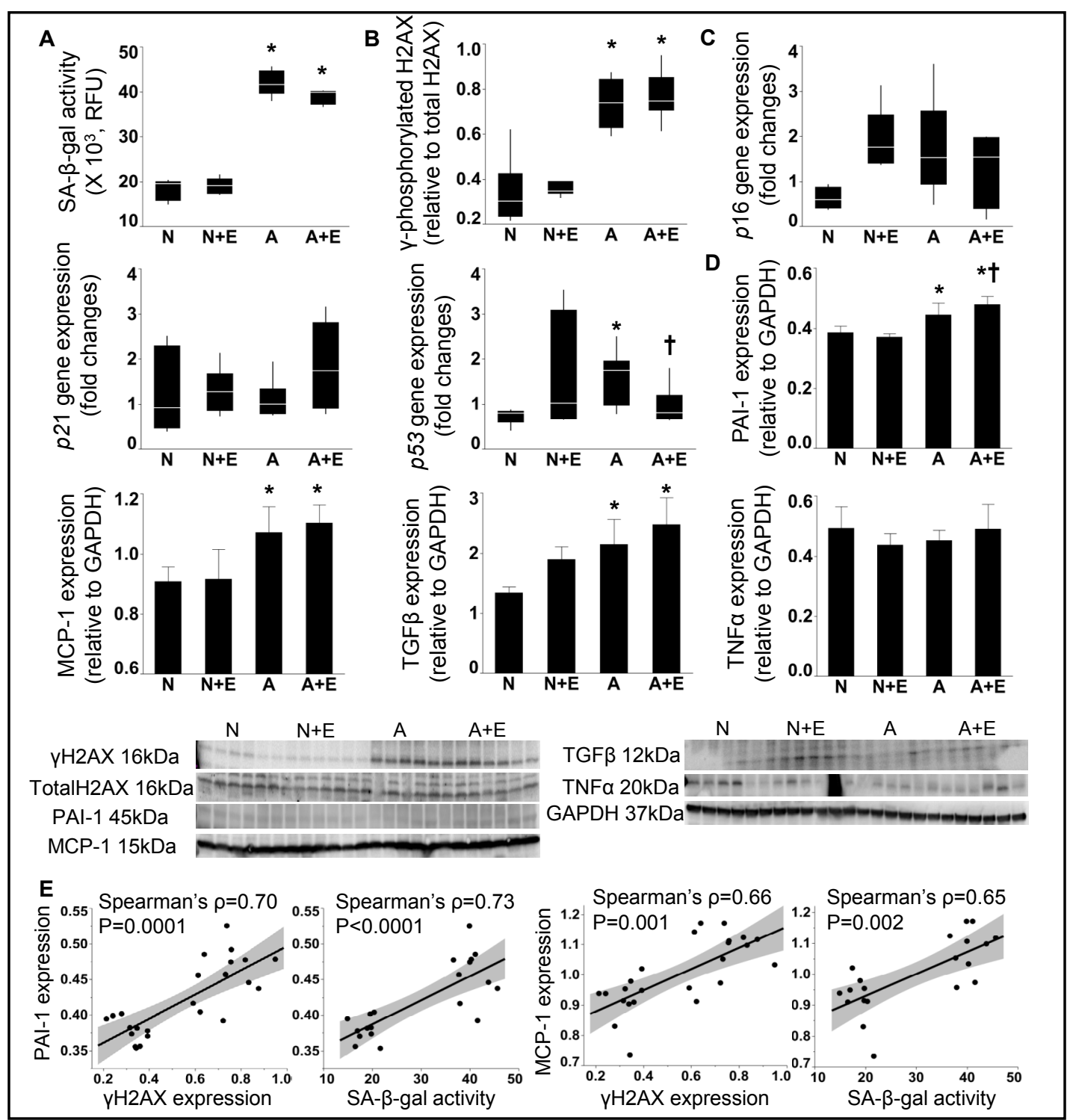

Fig. 6. Elamipretide decreases p53 gene expression in stenotic kidneys (STKs), whereas expression of $\gamma$-phosphorylated histone-2AX ( $\gamma \mathrm{H} 2 \mathrm{AX})$, PAI-1, MCP-1, and TGF $\beta$ remained unaltered. A. Renal SA- $\beta$-Gal enzyme activity was elevated in atherosclerotic renal artery stenosis (ARAS) and ARAS+elamipretide, and only slightly decreased by elamipretide. B. $\gamma \mathrm{H} 2 \mathrm{AX}$ activation in ARAS remained unchanged in the ARAS+elamipretide kidney. C. Renal p16 and p21 gene expression did not differ among the groups, whereas p53 gene expression was increased in ARAS and decreased after elamipretide treatment. D. PAI-1, MCP-1 and TGF $\beta$ expression was upregulated in both ARAS and ARAS+elamipretide kidneys, while TNF $\alpha$ expression levels were not different among the groups. E. The expression of PAI-1 and MCP-1 levels was directly correlated with renal $\gamma \mathrm{H} 2 \mathrm{AX}$ expressions and SA- $\beta$-Gal activity. N, Normal; $\mathrm{N}+\mathrm{E}$, Normal+elamipretide; A, ARAS; A+E, ARAS+elamipretide. ${ }^{*} \mathrm{P}<0.05$ vs. Normal, $\uparrow \mathrm{P}<0.05$ vs. ARAS.

the groups $(\mathrm{P}=0.72)$. The expression levels of PAI-1 and MCP-1 were directly correlated with renal $\gamma \mathrm{H} 2 \mathrm{AX}$ expressions and SA- $\beta$-Gal activity (Fig. 6E). 


\section{Cellular Physiology Cell Physiol Biochem 2019;52:617-632 \\ \begin{tabular}{ll|l} 
and Biochemistry $10.33594 / 000000044$ & Published online: 26 March 2019 & $\begin{array}{l}\text { C } 2019 \text { The Author(s). Published by } \\
\text { Cell Physiol Biochem Press GmbH\&Co. KG }\end{array}$
\end{tabular} \\ Kim et al.: Elamipretide in Stenotic Kidneys}

\section{Discussion}

The current study shows that ARAS is associated with cellular senescence and accumulation of dysfunctional mitochondria in the STK. The mitochondrial-targeted peptide elamipretide restores mitophagy and biogenesis as well as mitochondrial cardiolipin, and improves renal function and redox status in the ARAS STK. However, elamipretide only partly alleviates cellular senescence. This finding argues against a strong causal relationship between mitochondrial dysfunction and cellular senescence in the early stage of ARAS.

One of the interesting observations in our study was that ARAS induced STK cellular senescence. We found that SA- $\beta$-Gal activity, $\mathrm{p} 16, \mathrm{SAHF}$, and $\gamma \mathrm{H} 2 \mathrm{AX}$ expression, representing accumulation of senescent cells [26], and levels of the SASP markers PAI-1 and MCP-1, and TGF $\beta$ expression [27], were all elevated in the ARAS STK. Furthermore, cellular proliferation failed to rise in the ARAS STK, despite ischemic renal injury. This observation may account for our previous finding of blunted apoptosis in stenotic ARAS kidneys [28], a characteristic of senescent cells [5].

The factors promoting senescence in the ARAS kidney may include factors like hypercholesterolemia, atherosclerosis, increased blood pressure, and renal ischemia. Highfat diet leads to vascular endothelial senescence, associated with prominent inflammation and endothelial dysfunction [29]. In more advanced atherosclerosis, complex mechanisms including telomere attrition, accumulated DNA damage, increased oxidative stress, and epigenetic modifications result in cellular senescence [30]. Notably, senescent cells exacerbate atherosclerosis at all stages, and clearing them leads to lesion regression [6]. In addition, high blood pressure and renin-angiotensin-aldosterone system activation induce senescence in renal tubular, glomerular, and interstitial cells, indicated by increased $p 16^{\text {INK4a }}$ expression through $p 38$-MAPK activation [31]. Cycle arrest may also be mediated by hypoxia-inducible factors induced by renal ischemia, which promote cellular senescence [32], and by aldosterone in tubular cells via a $p 53 / 21$-dependent pathway [33]. Hence, both atherosclerosis and renal ischemia in our model can induce cellular senescence in various cell types, including renal tubular, interstitial, and endothelial cells.

Moreover, increased oxidative stress and mitochondrial dysfunction might be related to cellular senescence. ROS induce DNA damage by adversely affecting nuclear DNA and proteins, and mitochondria are leading targets for ROS damage as well as a major source of ROS [34]. Oxidative stress activates p53-signalling, which mediates the antiproliferative cellular responses including senescence [35]. Indeed, $p 53$ gene expression was upregulated in the ARAS STK and, further, directly correlated with SA- $\beta$-Gal activity. Tumor suppressor pathways like $p 16$ are pivotal in engagement of senescence, but cytokine-signaling pathways can also initiate senescence [36]. We detected no significant changes in $p 16 \mathrm{mRNA}$ expression, but observed upregulation of p16 protein expression in ARAS STK. This discrepancy between gene and protein expressions might be secondary to differences in protein translation and degradation rates [37]. In addition, at the early stage of ARAS senescence might involve primarily activation of $p 53$ and cytokine signaling, whereas the $p 16$ pathway plays a lesser role. Moreover, in many cell lines $p 21$ activation is temporary, and the level of this protein decreases after cell cycle arrest [38].

The pro-senescence and inflammatory milieu associated with autocrine and paracrine SASP is in turn implicated in tissue injury [39]. SASP cytokines involved in inflammation, monocyte chemotaxis, and proteolysis, which atherosclerosis contribute to pro-atherogenic process including extracellular matrix degradation and weakening of the vessel wall [6]. In our study, the role of PAI-1 and MCP-1 as SASP markers is underscored by the observation that their levels directly correlated with SA- $\beta$-Gal activity and $\gamma \mathrm{H} 2 \mathrm{AX}$ expression. We have previously shown that upregulated expression of MCP-1 in the STK contributes to functional and structural impairment by inflammatory cell infiltration, and its inhibition confers renoprotective effects [40]. We also found increased PAI-1 level in ARAS, suggesting that its biologic role including fibrinolytic inhibition might contribute to progression of atherosclerosis in ARAS [41]. A recent study has shown that TGF $\beta$, which was upregulated 


\section{Cellular Physiology Cell Physiol Biochem 2019;52:617-632 \\ \begin{tabular}{ll|l} 
and Biochemistry & $\begin{array}{l}\text { DOI: 10.33594/000000044 } \\
\text { Published online: } 26 \text { March } 2019\end{array}$ & $\begin{array}{l}\text { C } 2019 \text { The Author(s). Published by } \\
\text { Cell Physiol Biochem Press GmbH\&Co. KG }\end{array}$
\end{tabular} \\ Kim et al.: Elamipretide in Stenotic Kidneys}

in ARAS kidneys, also contributes cellular senescence of neighboring cells [42], as well as its pro-fibrotic effect. Thus, SASP may be responsible at least in part for kidney injury of ARAS.

We have also detected altered expression of proteins responsible for regulating mitochondria in the ARAS-STK. Our group has previously shown that increased mitochondrial ROS production is associated with peroxidation and loss of cardiolipin in ARAS [3]. Peroxidation of mitochondrial membrane phospholipids and thereby mitochondrial dysfunction are considered as contributors to age-related disease [43]. This study shows that the levels of the mitochondrial biogenesis regulators PGC-1 $\alpha$ and PPAR- $\alpha$ increased in ARAS, possibly to compensate for mitochondrial dysfunction, as were regulators of both fusion and fission. Previous studies suggest an overall shift toward fusion in senescent cells, allowing mitochondria to maintain ATP production and escape autophagy $[44,45]$. Pertinently, energy production levels in the ARAS STK appeared to be relatively preserved. The downregulated mitophagy markers in the ARAS STK, including increased P62 and decreased Parkin, may lead to accumulation of dysfunctional mitochondria that produce more ROS. Indeed, mitophagy activity is reduced in senescent cells $[46,47]$, as a result of lipofuscin accumulation and lysosomal dysfunction [48]. Taken together, the ARAS STK showed cardiolipin loss, altered mitochondrial dynamics, and defective mitophagy, yet sustained COX-4 activity and upregulated biogenesis regulators, which might be an adaptive compensatory response potentially associated with senescence in the early stage of ARAS.

Our group has previously demonstrated that mitoprotection achieved by restoring cardiolipin attenuated oxidative stress and injury of the kidney or heart in metabolic syndrome and ARAS $[3,19,20]$. Elamipretide prevents cardiolipin peroxidation through the inhibition of cytochrome-c peroxidase, improves electron carrier function, enhances ATP and decreases ROS production [49]. In this study, cardiolipin content was normalized, and oxidative stress ameliorated in the ARAS STK after elamipretide. Furthermore, elamipretide reinstated abnormally increased biogenesis and may have facilitated removal of dysfunctional mitochondria through activation of mitophagy in ARAS. Although both MFN-2 and DRP1 were increased in ARAS+ELAM, only DRP-1 expression was significantly higher than in ARAS, consistent with the suggestion that fission is a prerequisite for mitophagy [50,51].

Overall, Elamipretide normalized STK-RBF and GFR, and alleviated fibrosis in ARAS, as previously shown [3]. In our previous study, elamipretide improved renal microvascular remodeling and vascular endothelial function in ARAS [3]. In the current study we found that ARAS endothelial cells underwent senescence, which elamipretide slightly blunted, implying that senescence in endothelial cells might be linked to dysfunction of their mitochondria.

Interestingly, elamipretide decreased SA- $\beta$-Gal activity in ARAS, but not $\gamma \mathrm{H} 2 \mathrm{AX}$ activation. The lysosomal enzyme $\beta$-Gal is markedly increased in senescent cells, and when detectable at $\mathrm{pH} 6.0$ with the artificial substrate X-gal, is defined as SA- $\beta$-Gal [52]. While a commonly used senescence marker, in inflammatory conditions activated phagocytes can also increase $\beta$-Gal activity [52]. $\gamma \mathrm{H} 2 \mathrm{AX}$ is a sensitive marker for DNA double-strand breaks, although it has limited specificity for the phenotype in vivo [53]. A recent study has shown that mitochondrial dysfunction-associated senescence is not caused by accumulation of nuclear DNA damage, but by activation of 5'AMP-activated protein kinase and in turn $p 53$ [54]. Indeed, $p 53$ expression in this study was decreased after elamipretide treatment. Taken together, mitoprotection by elamipretide does not be seen to arrest DNA damage in the STK, but may partly blunt senescence by other pathways, including $p 53$. While elamipretide improves glomerular senescence and architecture in the kidney of aged mice, STK ischemic damage may be more pronounced and involve a multitude of mechanisms [55].

This study is limited by the small group sizes. Our swine ARAS model involves a short duration and early disease stage, yet incurs comparable renal alterations to those in human ARAS kidneys [15]. The relatively young age of the animals in the current study excludes effects of aging on senescence. Mitochondrial studies were performed in renal tissue, not specifically in renal senescent cells, which are difficult to isolate, limiting the ability to directly link mitochondrial changes and senescence. Hence, a firm cause-effect relationship between senescence and mitochondrial dysfunction in ARAS remains to be established. 


\section{Cellular Physiology Cell Physiol Biochem 2019;52:617-632 \\ \begin{tabular}{c|c|c|c|}
\hline DOl: 10.33594/000000044 & 2019 The Author(s). Published by \\
and Biochemistry &
\end{tabular} \\ Published online: 26 March 2019 Cell Physiol Biochem Press GmbH\&Co. KG \\ Kim et al.: Elamipretide in Stenotic Kidneys}

Further studies are needed to determine the precise cell type undergoing senescence. Lastly, whether elamipretide would impact long-term renal senescence warrants further investigation.

\section{Conclusion}

Mitochondrial protection improved renal function and alleviated tissue fibrosis, but only partly mitigated ARAS-induced cellular senescence. Mitochondrial dysfunction may not be the chief inducer of cellular senescence in early ARAS, possibly because of the multiple injurious pathways activated. Nevertheless, the impact of cellular senescence in ARAS on long-term renal functional and structural outcomes, and in turn application of senolytic strategies, remains to be considered.

\section{Acknowledgements}

This work was partly supported by NIH grants numbers: DK104273, HL123160, DK102325, DK120292 and DK106427, and by Stealth Biotherapeutics, Inc.

\section{Disclosure Statement}

The authors declare no potential conflicts of interest.

\section{References}

Safian RD, Textor SC: Renal-artery stenosis. N Engl J Med 2001;344:431-442. protection restores renal function in swine atherosclerotic renovascular disease. Cardiovasc Res 2014;103:461-472.

4 Zhu Y, Armstrong JL, Tchkonia T, Kirkland JL: Cellular senescence and the senescent secretory phenotype in age-related chronic diseases. Curr Opin Clin Nutr Metab Care 2014;17:324-328.

5 Zhu Y, Tchkonia T, Pirtskhalava T, Gower AC, Ding H, Giorgadze N, Palmer AK, Ikeno Y, Hubbard GB, Lenburg M, O’Hara SP, LaRusso NF, Miller JD, Roos CM, Verzosa GC, LeBrasseur NK, Wren JD, Farr JN, Khosla S, Stout MB, et al.: The Achilles' heel of senescent cells: from transcriptome to senolytic drugs. Aging Cell 2015;14:644-658.

6 Childs BG, Baker DJ, Wijshake T, Conover CA, Campisi J, van Deursen JM: Senescent intimal foam cells are deleterious at all stages of atherosclerosis. Science 2016;354:472-477.

7 Wang CY, Kim HH, Hiroi Y, Sawada N, Salomone S, Benjamin LE, Walsh K, Moskowitz MA, Liao JK: Obesity increases vascular senescence and susceptibility to ischemic injury through chronic activation of Akt and mTOR. Sci Signal 2009;2:ra11.

8 Rodrigues CE, Capcha JM, de Braganca AC, Sanches TR, Gouveia PQ de Oliveira PA, Malheiros DM, Volpini RA, Santinho MA, Santana BA, Calado RD, Noronha IL, Andrade L: Human umbilical cord-derived mesenchymal stromal cells protect against premature renal senescence resulting from oxidative stress in rats with acute kidney injury. Stem Cell Res Ther 2017;8:19.

9 Lopez-Otin C, Blasco MA, Partridge L, Serrano M, Kroemer G: The hallmarks of aging. Cell 2013;153:11941217.

10 Correia-Melo C, Marques FD, Anderson R, Hewitt G, Hewitt R, Cole J, Carroll BM, Miwa S, Birch J, Merz A, Rushton MD, Charles M, Jurk D, Tait SW, Czapiewski R, Greaves L, Nelson G, Bohlooly YM, Rodriguez-Cuenca S, Vidal-Puig A, et al.: Mitochondria are required for pro-ageing features of the senescent phenotype. EMBO J 2016;35:724-742. 


\section{Cellular Physiology Cell Physiol Biochem 2019;52:617-632

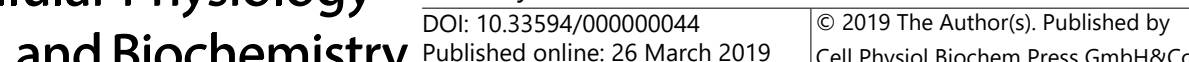 and Biochemistry Published online: 26 March 2019 Cell Physiol Biochem Press GmbH\&Co. KG \\ Kim et al.: Elamipretide in Stenotic Kidneys}

- 11 Herranz N, Gil J: Mitochondria and senescence: new actors for an old play. EMBO J 2016;35:701-702.

- 12 Korolchuk VI, Miwa S, Carroll B, von Zglinicki T: Mitochondria in Cell Senescence: Is Mitophagy the Weakest Link? EBioMedicine 2017;21:7-13.

- 13 Birk AV, Liu S, Soong Y, Mills W, Singh P, Warren JD, Seshan SV, Pardee JD, Szeto HH: The mitochondrialtargeted compound SS-31 re-energizes ischemic mitochondria by interacting with cardiolipin. J Am Soc Nephrol 2013;24:1250-1261.

14 Stulak JM, Lerman A, Porcel MR, Caccitolo JA, Romero JC, Schaff HV, Napoli C, Lerman LO: Renal vascular function in hypercholesterolemia is preserved by chronic antioxidant supplementation. J Am Soc Nephrol 2001;12:1882-1891.

15 Chade AR, Rodriguez-Porcel M, Grande JP, Krier JD, Lerman A, Romero JC, Napoli C, Lerman LO: Distinct renal injury in early atherosclerosis and renovascular disease. Circulation 2002;106:1165-1171.

16 Daghini E, Primak AN, Chade AR, Krier JD, Zhu XY, Ritman EL, McCollough CH, Lerman LO: Assessment of renal hemodynamics and function in pigs with 64-section multidetector CT: comparison with electronbeam CT. Radiology 2007;243:405-412.

17 Eirin A, Zhu XY, Krier JD, Tang H, Jordan KL, Grande JP, Lerman A, Textor SC, Lerman LO: Adipose tissuederived mesenchymal stem cells improve revascularization outcomes to restore renal function in swine atherosclerotic renal artery stenosis. Stem Cells 2012;30:1030-1041.

- 18 Zhang X, Li ZL, Eirin A, Ebrahimi B, Pawar AS, Zhu XY, Lerman A, Lerman LO: Cardiac metabolic alterations in hypertensive obese pigs. Hypertension 2015;66:430-436.

- 19 Eirin A, Woollard JR, Ferguson CM, Jordan KL, Tang H, Textor SC, Lerman A, Lerman LO: The metabolic syndrome induces early changes in the swine renal medullary mitochondria. Transl Res 2017;184:45-56. e9.

20 Eirin A, Ebrahimi B, Kwon SH, Fiala JA, Williams BJ, Woollard JR, He Q, Gupta RC, Sabbah HN, Prakash YS, Textor SC, Lerman A, Lerman LO: Restoration of Mitochondrial Cardiolipin Attenuates Cardiac Damage in Swine Renovascular Hypertension. J Am Heart Assoc 2016;5:pii:e003118.

21 Baker DJ, Childs BG, Durik M, Wijers ME, Sieben CJ, Zhong J, Saltness RA, Jeganathan KB, Verzosa GC, Pezeshki A, Khazaie K, Miller JD, van Deursen JM: Naturally occurring p16(Ink4a)-positive cells shorten healthy lifespan. Nature 2016;530:184-189.

22 Melk A, Kittikowit W, Sandhu I, Halloran KM, Grimm P, Schmidt BM, Halloran PF: Cell senescence in rat kidneys in vivo increases with growth and age despite lack of telomere shortening. Kidney Int 2003;63:2134-2143.

- 23 Kosar M, Bartkova J, Hubackova S, Hodny Z, Lukas J, Bartek J: Senescence-associated heterochromatin foci are dispensable for cellular senescence, occur in a cell type- and insult-dependent manner and follow expression of p16(ink4a). Cell Cycle 2011;10:457-468.

24 Berkenkamp B, Susnik N, Baisantry A, Kuznetsova I, Jacobi C, Sorensen-Zender I, Broecker V, Haller H, Melk A, Schmitt R: In vivo and in vitro analysis of age-associated changes and somatic cellular senescence in renal epithelial cells. PLoS One 2014;9:e88071.

25 Livak KJ, Schmittgen TD: Analysis of relative gene expression data using real-time quantitative PCR and the 2(-Delta Delta C(T)) Method. Methods 2001;25:402-408.

26 Dimri GP, Lee X, Basile G, Acosta M, Scott G, Roskelley C, Medrano EE, Linskens M, Rubelj I, Pereira-Smith 0, et al.: A biomarker that identifies senescent human cells in culture and in aging skin in vivo. Proc Natl Acad Sci U S A 1995;92:9363-9367.

27 Xu M, Tchkonia T, Ding H, Ogrodnik M, Lubbers ER, Pirtskhalava T, White TA, Johnson KO, Stout MB, Mezera V, Giorgadze N, Jensen MD, LeBrasseur NK, Kirkland JL: JAK inhibition alleviates the cellular senescenceassociated secretory phenotype and frailty in old age. Proc Natl Acad Sci U S A 2015;112:E6301-6310.

28 Chade AR, Rodriguez-Porcel M, Grande JP, Zhu X, Sica V, Napoli C, Sawamura T, Textor SC, Lerman A, Lerman LO: Mechanisms of renal structural alterations in combined hypercholesterolemia and renal artery stenosis. Arterioscler Thromb Vasc Biol 2003;23:1295-1301.

29 Shi Q Hornsby PJ, Meng Q Vandeberg JF, Vandeberg JL: Longitudinal analysis of short-term high-fat diet on endothelial senescence in baboons. Am J Cardiovasc Dis 2013;3:107-119.

30 Wang JC, Bennett M: Aging and atherosclerosis: mechanisms, functional consequences, and potential therapeutics for cellular senescence. Circ Res 2012;111:245-259. 


\section{Cellular Physiology Cell Physiol Biochem 2019;52:617-632 \begin{tabular}{c|c|c|c|}
\hline DOI: 10.33594/000000044 & (O) 2019 The Author(s). Published by \\
\hline
\end{tabular} and Biochemistry Published online: 26 March 2019 Cell Physiol Biochem Press GmbH\&Co. KG \\ Kim et al.: Elamipretide in Stenotic Kidneys}

31 Westhoff JH, Hilgers KF, Steinbach MP, Hartner A, Klanke B, Amann K, Melk A: Hypertension induces somatic cellular senescence in rats and humans by induction of cell cycle inhibitor p16INK4a. Hypertension 2008;52:123-129.

- 32 Hubbi ME, Semenza GL: Regulation of cell proliferation by hypoxia-inducible factors. Am J Physiol Cell Physiol 2015;309:C775-782.

33 Fan YY, Kohno M, Hitomi H, Kitada K, Fujisawa Y, Yatabe J, Yatabe M, Felder RA, Ohsaki H, Rafiq K, Sherajee SJ, Noma T, Nishiyama A, Nakano D: Aldosterone/Mineralocorticoid receptor stimulation induces cellular senescence in the kidney. Endocrinology 2011;152:680-688.

34 Kudryavtseva AV, Krasnov GS, Dmitriev AA, Alekseev BY, Kardymon OL, Sadritdinova AF, Fedorova MS, Pokrovsky AV, Melnikova NV, Kaprin AD, Moskalev AA, Snezhkina AV: Mitochondrial dysfunction and oxidative stress in aging and cancer. Oncotarget 2016;7:44879-44905.

35 Gambino V, De Michele G, Venezia O, Migliaccio P, Dall'Olio V, Bernard L, Minardi SP, Della Fazia MA, Bartoli D, Servillo G, Alcalay M, Luzi L, Giorgio M, Scrable H, Pelicci PG, Migliaccio E: Oxidative stress activates a specific p53 transcriptional response that regulates cellular senescence and aging. Aging Cell 2013;12:435445.

36 Kandhaya-Pillai R, Miro-Mur F, Alijotas-Reig J, Tchkonia T, Kirkland JL, Schwartz S: TNFalpha-senescence initiates a STAT-dependent positive feedback loop, leading to a sustained interferon signature, DNA damage, and cytokine secretion. Aging (Albany NY) 2017;9:2411-2435.

- 37 Raj A, Peskin CS, Tranchina D, Vargas DY, Tyagi S: Stochastic mRNA synthesis in mammalian cells. PLoS Biol 2006;4:e309.

38 Romanov VS, Pospelov VA, Pospelova TV: Cyclin-dependent kinase inhibitor p21(Waf1): contemporary view on its role in senescence and oncogenesis. Biochemistry (Mosc) 2012;77:575-584.

- 39 Hoare M, Narita M: Transmitting senescence to the cell neighbourhood. Nat Cell Biol 2013;15:887-889.

- 40 Zhu XY, Chade AR, Krier JD, Daghini E, Lavi R, Guglielmotti A, Lerman A, Lerman LO: The chemokine monocyte chemoattractant protein-1 contributes to renal dysfunction in swine renovascular hypertension. J Hypertens 2009;27:2063-2073.

41 Park MY, Herrmann SM, Saad A, Eirin A, Tang H, Lerman A, Textor SC, Lerman LO: Biomarkers of kidney injury and klotho in patients with atherosclerotic renovascular disease. Clin J Am Soc Nephrol 2015;10:443-451.

42 Hoare M, Ito Y, Kang TW, Weekes MP, Matheson NJ, Patten DA, Shetty S, Parry AJ, Menon S, Salama R, Antrobus R, Tomimatsu K, Howat W, Lehner PJ, Zender L, Narita M: NOTCH1 mediates a switch between two distinct secretomes during senescence. Nat Cell Biol 2016;18:979-992.

- 43 Spiteller G: Lipid peroxidation in aging and age-dependent diseases. Exp Gerontol 2001;36:1425-1457.

- 44 Ziegler DV, Wiley CD, Velarde MC: Mitochondrial effectors of cellular senescence: beyond the free radical theory of aging. Aging Cell 2015;14:1-7.

- 45 Gomes LC, Di Benedetto G, Scorrano L: During autophagy mitochondria elongate, are spared from degradation and sustain cell viability. Nat Cell Biol 2011;13:589-598.

46 Dalle Pezze P, Nelson G, Otten EG, Korolchuk VI, Kirkwood TB, von Zglinicki T, Shanley DP: Dynamic modelling of pathways to cellular senescence reveals strategies for targeted interventions. PLoS Comput Biol 2014;10:e1003728.

- 47 Garcia-Prat L, Martinez-Vicente M, Perdiguero E, Ortet L, Rodriguez-Ubreva J, Rebollo E, Ruiz-Bonilla V, Gutarra S, Ballestar E, Serrano AL, Sandri M, Munoz-Canoves P: Autophagy maintains stemness by preventing senescence. Nature 2016;529:37-42.

48 Terman A, Dalen H, Eaton JW, Neuzil J, Brunk UT: Aging of cardiac myocytes in culture: oxidative stress, lipofuscin accumulation, and mitochondrial turnover. Ann N Y Acad Sci 2004;1019:70-77.

49 Szeto HH, Birk AV: Serendipity and the discovery of novel compounds that restore mitochondrial plasticity. Clin Pharmacol Ther 2014;96:672-683.

- 50 Twig G, Elorza A, Molina AJ, Mohamed H, Wikstrom JD, Walzer G, Stiles L, Haigh SE, Katz S, Las G, Alroy J, Wu M, Py BF, Yuan J, Deeney JT, Corkey BE, Shirihai OS: Fission and selective fusion govern mitochondrial segregation and elimination by autophagy. EMBO J 2008;27:433-446.

- 51 Gomes LC, Scorrano L: High levels of Fis1, a pro-fission mitochondrial protein, trigger autophagy. Biochim Biophys Acta 2008;1777:860-866.

- 52 Sharpless NE, Sherr CJ: Forging a signature of in vivo senescence. Nat Rev Cancer 2015;15:397-408. 


\section{Cellular Physiology Cell Physiol Biochem 2019;52:617-632}

\begin{tabular}{ll|l} 
and Biochemistry & $\begin{array}{l}\text { DOl: 10.33594/000000044 } \\
\text { Published online: 26 March 2019 }\end{array}$ & $\begin{array}{l}\text { O } 2019 \text { The Author(s). Published by } \\
\text { Cell Physiol Biochem Press GmbH\&Co. KG }\end{array}$ \\
\cline { 2 - 3 } & King
\end{tabular}

Kim et al.: Elamipretide in Stenotic Kidneys

53 Ji J, Zhang Y, Redon CE, Reinhold WC, Chen AP, Fogli LK, Holbeck SL, Parchment RE, Hollingshead M, Tomaszewski JE, Dudon Q, Pommier Y, Doroshow JH, Bonner WM: Phosphorylated fraction of H2AX as a measurement for DNA damage in cancer cells and potential applications of a novel assay. PLoS One 2017;12:e0171582.

- 54 Wiley CD, Velarde MC, Lecot P, Liu S, Sarnoski EA, Freund A, Shirakawa K, Lim HW, Davis SS, Ramanathan A, Gerencser AA, Verdin E, Campisi J: Mitochondrial Dysfunction Induces Senescence with a Distinct Secretory Phenotype. Cell Metab 2016;23:303-314.

55 Sweetwyne MT, Pippin JW, Eng DG, Hudkins KL, Chiao YA, Campbell MD, Marcinek DJ, Alpers CE, Szeto HH, Rabinovitch PS, Shankland SJ: The mitochondrial-targeted peptide, SS-31, improves glomerular architecture in mice of advanced age. Kidney Int 2017;91:1126-1145. 